\title{
Joža Lovrenčič in makaronska latinščina v Sholarju iz Trente
}

\section{Anja Božič゙ in David Movrin**}

Slovenska literarna zgodovina se pri Jožu Lovrenčiču osredotoča predvsem na njegovo mladostno liriko. ${ }^{1}$ Ta je večinoma zajeta $\mathrm{v}$ pesniški zbirki Deveta dežela (1917), ki jo omenjajo vsi glavni slovenski literarnovedni priročniki, ${ }^{2}$ njegove pesmi najdemo v vseh pomembnejših antologijah slovenske lirike. Uvrščajo jih med prve ekspresionistične zbirke, Lovrenčiča štejejo za začetnika svobodnega verza. ${ }^{3}$ Vendar pa je lirika le manjši del njegovega obsežnega literarnega opusa. Kvantitativno gledano je večina njegovih prejšnjih in kasnejših pesmi pisana v klasični obliki; obenem je bil Lovrenčič veliko bolj produktiven kot pisec pripovednih del. ${ }^{4}$ Ta so obravnavana redkeje in na prvi pogled ne izstopajo. Nosijo pa poseben pečat Lovrenčičeve individualnosti, ki tu izstopa celo bolj kot pri njegovi ekspresionistični poeziji v svobodnem verzu. Pomemben element je tu njegova velika razgledanost na področju literarnega izročila, zlasti klasične filologije. Hkrati ta dela prikazujejo močan vpliv sočasnih tako zgodovinskih kot njegovih osebnih življenjskih prelomnic in s tem posredujejo niz avtobiografskih informacij. Tako zgovorno upodabljajo Lovrenčičevo kompleksno osebnost in tesno povezanost

* Oddelek za srednjeveške študije CEU, Nador u. 9, Budimpešta, anjaa.bbozic@gmail.com

** Oddelek za klasično filologijo na Filozofski fakulteti Univerze v Ljubljani, Aškerčeva 2, Ljubljana, david.movrin@ff.uni-lj.si

1 Branko Melnik, »Staro in novo v pesniškem opusu Joža Lovrenčiča«, 69.

2 Seznam v članku, ki ga je objavil Darinko Kores, "Joža Lovrenčič: Sholar iz Trente: ob štiridesetletnici pisateljeve smrti«, pregled različnih ocen njegovega ustvarjanja pa v predgovoru Jožeta Faganela ob izdaji Lovrenčičevih pisem, Joža Lovrenčič, Ves vaš ljubeči očka: Pisma hčerki Nini.

3 Aleksander Bjelčevič, „Slovenski svobodni verz do sredine tridesetih let 20. stoletja $\ll, 103$.

4 Melnik, »Staro in novo v pesniškem opusu«, 69. 
njenih glavnih sfer: to so globoka pripadnost krščanstvu, neomajna pedagoška vztrajnost in izredna afiniteta do sveta rimske in grške antike. Vse to se je povsem naravno prepletlo $\mathrm{z}$ njegovim ustvarjanjem, o čemer priča tudi spontano jezikovno prehajanje v njegovih delih.

\section{BIOGRAFSKE OKOLIŠČINE}

V Kredu pri Kobaridu rojeni Lovrenčič se je s klasično kulturo in še posebej z latinščino srečeval že od otroštva. Šolal se je na goriški gimnaziji in je prvo leto stanoval v Alojzijevišču, do sedmega razreda pa $\mathrm{v}$ malem semenišču, saj naj bi na materino globoko željo postal duhovnik. Žilico za pisanje je imel že kot otrok, kot v povesti Med Scilo in Karibdo (1930) pravi sam, ${ }^{5}$ in že v šoli je pisal in urejal »dva nekaka politična lista, dva leposlovna, ilustrirana«. ${ }^{6}$ Po izstopu iz semenišča je v Gorici dobil še več veselja in skupaj s šolskimi tovariši je urejal ter pesnikoval v vrsti rokopisnih listov, ki so jih pripravljali skrivaj, da vodstvo šole ali semenišča ne bi poseglo vmes. ${ }^{7}$ Do mature leta 1910 je imel objavljenih že precej pesmi in drugih literarnih del. Navdih in zgled je sprva iskal pri starejših slovenskih avtorjih, ki jih je $\mathrm{z}$ zanosom bral že v dijaških letih. ${ }^{8}$ Kasneje je po Župančičevem zgledu vzpostavil nov odnos do ritma in metruma, ${ }^{9}$ nato pa se usmeril v strnjen in slikovit ekspresionizem, formalno pa prešel k svobodnemu verzu. ${ }^{10} \mathrm{~V}$ letih 1913-1917 je spisal, nato pa v omenjeni pesniški zbirki Deveta dežela tudi objavil glavni del svoje ekspresionistične poezije. ${ }^{11}$ Kasneje je njegova ustvarjalnost v tej smeri polagoma zamirala in v letih 1918-20 je v Domu in svetu objavil le še nekaj ekspresionističnih pesmi. Ves čas pa je objavljal

6 Nepodpisana študija "Elementi ekspresionizma pri Joži Lovrenčiču«, v: Arhiv Joža Lovrenčiča (Oddelek za klasično filologijo, FF UL), 3 .

7 V povesti Med Scilo in Karibdo najdemo opis, kako je mladi dijak pod mizo skrival novo številko Ljubljanskega zvona, da je ne bi odkrili predstojniki v domu. Prav zaradi takšnega občutka utesnjenosti je iz Alojzijevišča izstopil že pred maturo; Lovrenčič, Med Scilo in Karibdo, 40.

8 Njegove najzgodnejše pesmi se gibajo med impresionizmom in novo romantiko in skoraj v vsaki je jasno razločen vzor enega ali več starejših pesnikov, Gregorčiča, Aškerca, Ketteja, Meška ali Prešerna. Prim. Slodnjak, Slovensko slovstvo, 365. Melnik, »Staro in novo v pesniškem opusu Joža Lovrenčiča«, 70.

10 Ivan Grafenauer, »O naših najmlajših«, 6-10.

11 "Elementi ekspresionizma pri Joži Lovrenčiču«, 4. 
še vrsto drugačnih izdelkov: članke, pesmi v tradicionalni verzni obliki, pripovedi po usmeritvah Mohorjeve družbe, zgodovinske romane in prevode. ${ }^{12}$ Še vedno je pisal tudi izpovedno poezijo, a njegove glavne smernice se obrnejo v pripovedništvo, tako v pesništvu kot tudi v prozi, s prevlado folklornih in zgodovinskih tem.

Po zaključku študija slovenistike in klasične filologije v Gradcu je nekaj časa učil slovenščino na gimnaziji v Gorici, ${ }^{13}$ ko pa so po vojni oblasti zaprle goriško gimnazijo, se je preselil sprva v Kranj, nato v Podnart in zatem v Ljubljano. Od leta 1920 služboval kot učitelj na Prvi gimnaziji (Poljane), nato od leta 1930 na Tretji gimnaziji (Bežigrad) in od leta 1939 na učiteljišču (Ledina). V tem času je nastala večina njegovih pripovednih in dramskih del, med drugim tudi v nadaljevanju obravnavani dve, ${ }^{14}$ poleg tega pa se je uveljavil kot literarnokulturni zgodovinar in prevajalec. Prevajal je predvsem iz italijanščine, med drugim pa tudi iz stare grščine, in sicer Lukijana.

Leta 1944 se je Lovrenčič na željo tamkajšnjih izobražencev vrnil v Gorico in prevzel ravnateljstvo na ponovno ustanovljeni slovenski gimnaziji. ${ }^{15}$ Njegovo delovanje je izzvalo politično obsodbo s strani OF in kmalu po koncu vojne je bil obsojen in zaprt - kot je desetletja kasneje ugotovilo sodišče, povsem po krivici. Z javnim blatenjem je začel kar Lovrenčičev dolgoletni prijatelj, boter njegove hčere in sodelavec pri Domu in svetu France Bevk, ki je slovensko gimnazijo v Gorici označil za nič manj kot »fašistični strup «. ${ }^{16} \mathrm{Ob}$ tožbe so Lovrenčiča globoko prizadele. S koncem semestra se je vrnil v Ljubljano, kjer je zaradi bolezni ostal dlje, kot je nameraval, nato pa se v Gorico ni mogel več vrniti, saj je njegovo tamkajšnje stanovanje uničila bomba. Ob koncu vojne se je v vsesplošni paniki na zahtevo družine umaknil v Celovec, od koder je nameraval nazaj v Gorico. Z ženo in eno izmed hčera je kot civilist potoval $z$ enim od transportov, ki so s Koroške vozili slovenske domobrance, vendar pa je vlak namesto v obljubljeno Italijo zapeljal v predor Podrožca in nato na Jesenice, kjer ga je pričakala partizanska vojska. Tu je bil

Celotno bibliografijo Lovrenčičevih objavljenih del je zbral Marijan Brecelj, »Bibliografija Jože Lovrenčiča«, 125-58.

Takrat se je tematsko posvečal predvsem folklori s Tolminskega; leta 1921 izda zbirko Gorske pravljice, ki jih Dolenc opisuje kot »ljudske povedke in vraže v verzih, in to Lovrenčičevih «, in izražajo globoko občudovanje do domače pokrajine in njenega izročila. Janez Dolenc, »Folklorne prvine v delih Joža Lovrenčiča", 90.

4 Na primer v zbirki legend v prozi Tiho življenje iz leta 1939.

David Movrin, »Dr. Joža Lovrenčič in njegove zakopane Metamorfoze«, 66.

France Bevk, »Fašistični strup«, Partizanski dnevnik 23. januarja 1945. 
Lovrenčič že določen za pot v smrt, ko ga je prepoznal nekdanji učenec, zdaj partizanski častnik, in mu rešil življenje. V Ljubljani je bil nato obsojen zaradi nasprotovanja OF, sledil je vnaprej odločen proces in Lovrenčič je bil zaprt ter obsojen na prisilno delo. Ko je bil leto kasneje izpuščen, je ostal brez pravice do pokojnine, zaposlitve in imena. Ni smel več objavljati, njegove knjige pa je Komisija za pregled knjižnic umestila na seznam prepovedanih knjig. ${ }^{17}$

Sovraštvo, naperjeno proti njemu in njegovi družini, pa ni ustavilo njegove ustvarjalnosti. Še naprej je pisal, predvsem epiko in krajše lirske pesmi. V njih sam sebe označuje $\mathrm{z}$ nadimkom »Nič Niče«, ki ga pogosto uporablja tudi v zasebnih pismih. Prav ta besedna zveza služi tudi kot naslov za neobjavljeno tipkopisno pesniško zbirko iz leta 1949. Tipkopis zbirke se s še nekaterimi drugimi neobjavljenimi Lovrenčičevimi deli nahaja v zapuščini, ki jo je do nedavnega hranila Marta Vovko, vdova Lovrenčičevega vnuka dr. Andreja Vovka. Mapo z zapuščino je prinesla na Oddelek za klasično filologijo spomladi leta 2018, po izidu zadnjih treh knjig Metamorfoz v Lovrenčičevem prevodu. ${ }^{18} \mathrm{~V}$ pretresljivem pričevanju je povedala, da je njen mož gradivo pred smrtjo položil na vrh svojih dokumentov in ji ga s tem zaupal v najpozornejšo skrb. V mapi je poleg omenjenega tipkopisa še nekaj beležk Lovrenčičevih mladostnih pesmi iz leta 1907, nekaj krajših besedil drugih avtorjev, nekateri dokumenti in članki, povezani z Lovrenčičevo obsodbo, različne fotografije in celo arhitekturni tloris pred vojno načrtovane hiše, kamor naj bi se preselili z družino.

Lovrenčič je bil namreč po izpustu iz zapora leta 1946 zaradi prepovedi objavljanja obsojen na svojevrstno notranje izgnanstvo, zaradi uvrstitve na seznam prepovedanih avtorjev pa tudi na sodobno inačico antične damnatio memoriae, torej na vsesplošno zamolčanost. Poleg omenjene zbirke lirskih pesmi Nič Niče sta neobjavljeni ostali še dve deli, epska pesnitev Brat Honorat in prevod Ovidijevih Metamorfoz, ki se mu je posvečal zadnji dve leti pred smrtjo (1954). Zadnjih devet knjig njegovega prevoda je nedavno izšlo v reviji Keria. ${ }^{19}$ Ob dvatisočletnici Ovidijeve smrti v izgnanstvu bo tako Metamorfoze slednjič tudi v slovenščini mogoče brati v celoti. 
Tako prevod kot drugi dve deli prikazujejo Lovrenčičevo zavezanost klasični kulturi in antiki, ki mu je v letih po obtožbi morda služila tudi kot svojevrstna opora. V eni od pesmi zbirke Nič Niče najdemo Horacijev citat v izvirniku: »Impavidum ferient ruinae, / če svet bi zrušil se, podrl - / tak mož res ne premine / ko je iz bistva vrl« $(38,9-12) .{ }^{20}$ Slednje kaže, kako se včasih tudi v izpovednih pesmih ni mogel odpovedati neposrednim prehodom $\mathrm{v}$ jezik, ki mu je posvetil svojo poklicno pot. Navedeni verzi niso osamljen primer, podobno je denimo v voščilnem sonetu, posvečenem Francetu Koblarju: »Šest težkih križev nosiš že na rami, / elegantiarum arbiter, vzravnano / in delaven kot redko kdo med nami« $(21,9-11){ }^{21}$ (Je mogoče, da referenca na Petronija in njegovo nevarno krmarjenje med udinjanjem oblasti in prezirom do nje ni bila zgolj naključje?) Pri tem ne gre za jezikovno mešanje v smislu žanra, je pa latinščine precej več v dveh zgodnejših delih, v povesti Med Scilo in Karibdo in v epski pesnitvi Sholar iz Trente. Še posebej zadnja prehaja v latinščino tako pogosto, da lahko govorimo o pojavu, ki ga literarna zgodovina imenuje makaronska latinščina. ${ }^{22}$

Zametke tega pristopa je mogoče najti že v avtobiografski povesti Med Scilo in Karibdo, ki prinaša tudi največ podatkov o Lovrenčičevem odraščanju za časa šolanja do mature in o prvih srečanjih s klasičnim izročilom. Objavil jo je v Mentorju 1928/29 pod izmišljenim imenom $^{23}$ kot zbir vloženih zgodb, ki mu jih pripoveduje prijatelj. Vendar pa je iz besedila jasno, da gre pravzaprav za »njegov lastni dijaški življenjepis od gimnazijske pripravnice do mature«, opisuje pa »svojo borbo za poklic: ali duhovnik ali kaj drugega«. ${ }^{24}$

Resnično bi bila lahko že ta povest slogovna predhodnica Sholarja iz Trente. V njej namreč mrgoli latinskih citatov, ki živo ponazarjajo tesno prisotnost klasične kulture med šolanjem slovenskih

"Nič Niče«, v: Arhiv Jože Lovrenčiča (1949).

Ibid.

Gantar, »Joža Lovrenčič in antika«, 99.

In sicer J. K. Rejec; ob drugačni vezavi črk je to J(oža) Krejec, to je Joža iz Kreda. Lovrenčič, Med Scilo in Karibdo, 65.

Ibid. Tesna zavezanost krščanskemu izročilu se ni pri njem nikoli pretrgala, vendar pa se je v osmem razredu odločil za izstop iz semenišča: »Življenje v semenišču je pustilo $\mathrm{v}$ njem trajne sledove, ki se očitno kažejo tudi v njegovem literarnem ustvarjanju in v njegovem religioznem svetovnem nazoru. Od tod izvira njegova ljubezen do latinskih besed, ki jih je v obilici raztresel po svojih delih, od tod tudi uporaba metafor iz Biblije, tu je tudi korenina njegovi epski pesnitvi - Trentarski študent.« Iz nepodpisane rokopisne razprave »Elementi ekspresionizma pri Joži Lovrenčiču«, 3 . 
gimnazijcev ob začetku stoletja. Že v prvem odstavku med napovedjo teme iz študentskega življenja kar trikrat spontano preide $\mathrm{v}$ latinščino:

Saj je to življenje lepo in pisano in zajemljivo - Debevec, Finžgar, Cankar docent - nešteto junakov se ti ponuja, da bi jih ovekovečil, laudator temporis acti, novim generacijam v eksempel, a ko bi videli svojo podobo, kdo ve, kaj bi se mi primerilo, pa čeprav bi jih idealiziral, da bi lahko veseli in ponosno vzklikali: »Fuimus Troes! ${ }^{25}$

Za vsakega od latinskih izrazov sledi opomba, v kateri Lovrenčič citat prevede in včasih tudi razloži v kontekstu: »Fuimus Troes! Bili smo Trojanci! To se pravi: postavili smo se. ${ }^{26}$ Prisotna je tudi grščina - takole opisuje, kako je med prikritim branjem nove izdaje Zvona napol zamudil večerjo:

[...] sem se zamaknil v branje, iz katerega me je vzdramil zadovoljen smeh »conmensalium «. Molče so me bili pri zajemanju preskočili in ker je pri skledi računal vsak s svojim zdravim želodcem, ki દ̉v

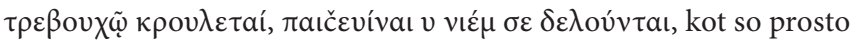
po Homerju tedaj večkrat ugotavljali, nisem imel iz prazne sklede kot zadnji več kaj zajeti. Da bi se pritožil? Izdati bi se moral - to pa je bilo še hujše nego prazen krožnik. Potrpel sem in bral dalje, dokler niso prinesli prikuhe, pri kateri sem plačal »milo z dragim«, ker ob sami Zvonovi liriki in prozi nisem bil - sit venia verbo - sit $[. . .]^{27}$

$\mathrm{V}$ opombi nato transkribira poved $\mathrm{v}$ grškem alfabetu in prevede latinski izraz ter frazem. Zgornji odlomek lepo ponazarja dva načina, na katera Lovrenčič brez posebnega zaznamka razen znaka za opombo v besedilo spontano vpleta predvsem latinščino. Včasih posamezno slovensko besedo nadomesti z latinsko (conmensalium), seveda v ustreznem številu in sklonu (tu na primer svojilni genitiv), drugič uporabi latinsko frazo ali pregovor - občasno celo tako, da funkcionirata pomen in zven besede hkrati, kot zgoraj pri »sit venia verbo ${ }^{28}$ - ali pa v latinščini napiše stavek, ki je slovnično povsem prilagojen poteku slovenske povedi, npr. »Jaz sem svoje navdušenje še isti večer izlil $v$ verze in jih skrbno prepisal v notes, $v$ katerem

Lovrenčič, Med Scilo in Karibdo, 5.

Ibid., 65 .

Ibid., 40.

Kar pomeni »naj bo oproščeno izrazu«, hkrati pa je konjunktivna oblika glagola esse homonimna slovenskemu pridevniku sit. 
danes z obledelimi črkami pričajo, quo sint tempore nati ... ${ }^{29}$ Prav takšno spontano prehajanje med jezikoma in prilagajanje latinskih delov stavi v slovenskih povedih je posebnost tega besedila, saj ga razlikuje od tekstov, $\mathrm{v}$ katerih prav tako najdemo latinske pregovore in fraze, a tako, da se jasno razločijo od siceršnjega poteka besedila. Še mnogo značilnejše je to za nekatere speve obsežnejšega Lovrenčičevega dela Sholar iz Trente.

\section{SLOVENSKI FAUST}

Epsko pesnitev Sholar iz Trente je Lovrenčič sprva izdajal po odlomkih v Mentorju (1916) in Domu in svetu (1921-1922), nato pa leta 1939 tudi v knjižni obliki. Čas dogajanja je konec 16. stoletja, kraj pa področje Beneške republike med današnjo Primorsko, Vidmom in Padovo. Zgodovinsko okolje - čas beneško-habsburške vojne - nastavi ogledalo času nastanka, torej prvi svetovni vojni, soški fronti in fašistični diktaturi. Pesnitev sledi življenju trentarskega kmečkega sina, ki se na materino željo poda $\mathrm{v}$ Videm, da bi študiral za duhovniški poklic. Vendar pa se od tega odvrne in se v hudi sili zaradi lakote in pomanjkanja $\mathrm{v}$ zameno za denar zapiše hudiču. Leta kasneje se vrne domov in prizna, da ne bo postal duhovnik, zaradi česar se mu starša odpovesta. Po smrti izvoljenke se priporoči Mariji in povzpne $\mathrm{v}$ domače gore, da bi se spokoril. Ko pride po njegovo dušo hudič, kliče mater, ki takrat umre, a njena molitev je uslišana in pogodba s hudičem se razdre, s čimer se konča prvi del pesnitve. Motiv študenta, ki se zapiše hudiču, je Lovrenčiča že v otroštvu očaral ravno zato, ker je bil v Sloveniji značilen le za njegove domače kraje. $^{30}$ Sklicuje se tudi na objavo Simona Rutarja, ki je legendo opisal leta $1882 \mathrm{v}$ Ljubljanskem zvonu. Lovrenčič jo razširi v neke vrste delni življenjepis glavnega protagonista v obliki epa, temu pa doda še precej manj živahen drugi del, kjer v obliki kronike popiše zgodovino Trente od odkritja rude v Trenti do posvetitve trentarske cerkve.

Za oblikovanost in vrstno oznako dela je bila ključna ciljna publika. Lovrenčič v svoji splošni opombi izraža upanje, da bo »Sholar iz Trente našel mnogo prijateljev - zlasti na naših gimnazijah. « ${ }^{31} \mathrm{Z} e$

Lovrenčič, Med Scilo in Karibdo, 17.

»Tako sem slišal že kot otrok doma zgodbo o šolarju iz Trente, ki se je hudiču zapisal. Edino v teh krajih je ta motiv doma." Iz avtorjevega pripisa, objavljenega v splošni opombi Joža Lovrenčič, Sholar iz Trente, 225.

1 Ibid., 227. 
res, da gre pri folklorni obarvanosti verjetno predvsem za prilagajanje okusu in zahtevam manj zahtevnim bralcem. A glede na snov, obseg in slog se Sholar zaradi svoje izredne informativnosti precej razlikuje od siceršnjih mohorjank prejšnjega stoletja. Lovrenčičeve podrobne opombe so nujno potrebne in odkrito poučne. Gre za navajanje geografskih pojmov, zgodovinskih dejstev, etnografskih značilnosti. Od vseh področij, ki se jim avtor posveča z naključno razsejanimi informacijami, je daleč najbolj prisotna antika. Najdemo obilico omemb antičnih mitov, pisateljev, historiografov, filozofov itd., poleg tega pa je besedilo prepleteno $\mathrm{z}$ latinskimi pasusi. Pri tem ne gre le za citate, temveč tudi daljše odlomke Lovrenčičevih avtorskih latinskih verzov. Ti se mojstrsko izmenjujejo s slovenskimi, in sicer tako v obliki daljših odlomkov kot tudi posameznih besed, ki so kot po naključju vpletene med slovensko besedilo, oboje pa je razloženo v spremni besedi. Npr. med opisom običaja iniciacije prvošolcev: »Haec clavis nostrae vita / si radovednost sita? [...] Zdaj pa res že vse veste / umáknite se s ceste / da do taberne pridemo / in prvikrat poskusimo / ta unicum speciale / kako odpre portale. ${ }^{32}$ Zatem sledi napitnica, ki jo bodoči študentje zapojejo v latinščini:

Ut semper nobis canes,

dulcissime Joannes,

bibe vinum ad libitum

non est, non est prohibitum

nec nocte nec diebus

dum lucet almus Phoebus! $!^{33}$

$\mathrm{V}$ spremni besedi nato najdemo razlago:

Ut semper nobis canes ...: Ut, kot veste, veže pravi latinec s konjunktivom, a tu so si pevci pač zaradi rime, dovolili futurum. Delali so tedaj v vsakdanji latinščini, ki so jo imenovali makaronščino, še hujše napake, ne da bi ne poznali Cicerona. Prevod pesmi bi bil: Da vedno boš nam pel / Joannes ves vesel / pij vino sladko, pij, / saj prepovedano nam ni / podnevi ne ponoči, / dokler je Phoebus v moči. ${ }^{34}$

Sholar Joannes s svojo družbo za grajsko gospodo devinskega gradu uprizori tudi komedijo, ki je prav tako popisana v pesnitvi, v spremni besedi pa avtor pojasni, da gre za improvizacijo, v kateri si študen- 
tje privoščijo prve grške filozofe in jih po svoje komentirajo. Glavna oseba je filozof Tales iz Mileta, ki odkriva, da je voda prapočelo vsega, medtem ko ga skušajo ostali prepričati, da je pomembnejše od vode vino. $V$ tem delu Lovrenčič popestri vloženo dramo tudi z nekaterimi grškimi izrazi v transkripciji. Tales reče: »Iz vode $-e k$ to hidati - je vse nastalo. Sluga pa mu s Pindarjem odgovarja: »Haha, kakor tvoj ariston to hidor? « ${ }^{35}$ Kasneje Solon pravi: »Ljubezni pesmi sem koval / in v boj za Salamino sem ljudi navduševal / in za zdravo sem postavo / oskrbel državo - / gerasko d' aei polla didaskomenos / čem reči, da v starosti sem spoznal, / kako lahko dobiti je dolg nos!« Svoje pove tudi Pitak: »Prijatelj Tales, vrč me spomnil moje je besede, / ki vedno in povsod drži: Metron ariston! Drži se zlate srede. ${ }^{36}$ Da bralci ne bi bili prikrajšani za komiko, ki temelji na poznavanju grških filozofov, $\mathrm{v}$ opombah navede tudi splošne podatke o vseh omenjenih avtorjih.

Nad izvedbo komedije je navdušen tudi grajski pater, ki se z Joannesom zaplete $\mathrm{v}$ - spet $\mathrm{z}$ latinskimi frazami prepreden - pogovor o njegovi domovini:

Haec meminisse juvat! Ne, ad rem!

Kar zdaj, Joannes, ti povem:

Ti jezik znaš, ki govoré ga tod,

saj do gorá prebiva isti rod,

in, ako prav sem poučen,

razširjen je ko drug noben

in Orbe, ko še sever, jug in vzhod

Slovencem v last je dal Gospod.

Oportet scire, jaz sem tu le malo let

in kakor se mi je priljubil svet,

se tudi ljudstvo mi je prikupílo

in dém, ljubezni več bi zaslužilo,

id est, sermone patrio vernaculo

bi moral bukve písati mu kdo,

a se nihčé tega ne spomni.

Propterea ne rideas, če ti izdam,

da jaz napisal rad bi sam

v jeziku vašem kaj v obliki skromni. ${ }^{37}$ 
Joannes in pater se nato poglobita $v$ iskanje kakršne koli informacije o slovenskem jeziku v knjigah in listinah grajske knjižnice in po dolgem pregledovanju naletita na zgodovinsko pričevanje, Chronicon acris locique a temporibus antiquis usque ad aetatem nostram - »Kroniko, letopis, zgodovino gradu in kraja od starodavnih časov do naše dobe«, kakor naslov prevaja ${ }^{38}$ spremna beseda. V njej bereta zgodovino Joannesovih domačih krajev od časa Argonavtov do ustoličevanja karantanskih knezov, skozi dogajanje pa preseva slavospev slovenskemu jeziku in ljudstvu. Tudi ta del se zaključi s patrovim makaronskim vzklikom, da si želi videti prvih zapisov v slovenščini, ki sta jo pisala Ciril in Metod: »Le pomisli, šeststo let je / že minilo, kar vaš jezik / sveta brata sta pisála / in vam prve knjige dala! / O, kakó bi rad jih videl, / če že ne typis impressis / tamen saltem manu scriptos! « ${ }^{39}$

Takšno povezovanje materinščine in latinščine ali celo grščine je za slovensko književnost novo. Kot izpostavlja Gantar, lahko sicer latinske citate srečamo tudi pri nekaterih drugih slovenskih piscih. ${ }^{40}$ Nenazadnje je že Prešeren Stanka Vraza zbodel z jezikovno mešanim epigramom z lukanovskim nadihom: "Victrix causa Diis placuit, sed victa Catoni; / Stanko Slovencev uskok, Vraz si narobe Katón." A kot pri Prešernu so latinski vložki tudi pri drugih piscih večinoma jasno ločeni od ostalega teksta. ${ }^{41}$ Nasprotno pa so pri Lovrenčiču meje zabrisane in govorica določenih literarnih oseb spontano prehaja v latinščino. Pri ostalih primerih v slovenščini gre v veliki meri za vstavljanje citatov, medtem ko pri Lovrenčiču velikokrat najdemo avtorske pasuse ali smiselno vstavljene latinske besede v primernem sklonu in številu. Tako Lovrenčič uvaja nov stilni žanr, ki ga Gantar imenuje »makaronska latinščina ${ }^{42}$

\section{MAKARONSKI SLOG IN NJEGOVI PROBLEMI}

Pri analizi makaronskih besedil že na samem začetku naletimo na terminološko težavo, saj »splošno sprejete definicije makaronskega sloga ni«. ${ }^{43}$ Izraz »makaronski jezik« zaznamuje jezikovno mešanje $\mathrm{v}$ besedilu, in sicer tako, da med deli v različnih jezikih ni posebne

Ibid., 227.

Ibid., 120.

Na primer v Jurčičevem Desetem bratu v govorici izobražencev in študentov in v izobilju pri Ivanu Preglju. Gantar, »Joža Lovrenčič in antika«, 99.

Prim. Pregljev roman Plebanus Joannes.

Gantar, »Joža Lovrenčič in antika«, 99.

Šime Demo, »Mining Macaronics«, 199. 
meje in se kontekst ne prekine, za razliko od besedil, sestavljenih iz jasno ločenih in samostojnih odlomkov v različnih jezikih. Zasilna vzporednica v govorjenem jeziku bi bilo lahko kodno preklapljanje. ${ }^{44}$ Običajno je tak izraz uporabljen $\mathrm{z}$ negativno konotacijo in večkrat zaznamuje del, kjer ima prehajanje humoren ali satiričen namen. ${ }^{45}$

»Makaronska latinščina« torej označuje žargonski kolaž besed iz ljudskega jezika, ki so pomešane $z$ latinskimi besedami ali pa so jim dodane latinske končnice. Tako pisana besedila se v Evropi začno pojavljati ob koncu srednjega veka, ko je bila latinščina delovni jezik klera in izobražencev, vendar je že izgubljala veljavo na račun ljudskih jezikov. Izraz »makaronski« zvira iz besede maccarona - mešanica testenin, ki je predstavljala vsakdanjo jed kmečkega prebivalstva. Z žanrom, ki ga označuje, je povezan prek naslova komične pesnitve Tifija Odasija Macaronea (1488/89), spisane v mešanici latinščine in italijanščine. ${ }^{46}$

Namen prvih tako zapisanih besedil je bil najverjetneje smešenje polomljene latinščine, ki so jo takrat uporabljali zdravniki, izobraženci in uradniki. Vzrok za nastanek njihove "makaronščine» bi bil lahko nevednost ali malomarnost, morda pa so tak jezik uporabljali tudi zato, da bi jih razumelo preprosto ljudstvo, ne da bi se bilo treba piscem povsem prilagoditi ljudski govorici. Vendar, kot opozarja Perini, makaronska latinščina, ki so jo uporabljali Odasi in drugi pisci tega žanra, nikakor ni takšna - kakor tudi njeni pisci niso nevedni ali malomarni, temveč se tako le avtoironično karikirajo. ${ }^{47}$ Že res, da je zasnovana na »skvarjeni« latinščini neukih, a njena satiričnost in humor sta lahko v polni meri dostopna le tistim, ki sicer obvladajo tudi pravilno latinščino. ${ }^{48} \mathrm{Na}$ podlagi tega jo je treba razlikovati od »kuhinjske latinščine«, Küchenlatein, imenovane tudi latinus grossus, iz poznega 14. stoletja, ki je v tistem času funkcionirala kot nekakšna lingua franca, mešanica latinščine in vsakdanjega vulgarnega jezika, namenjena nujni komunikaciji v določenih kontekstih. Ta je bila predvsem jezik mestnih birokratov, pravnikov, pridigarjev in univerzitetnih tajnikov, ki je spadal v točno določena okolja. Jezikovna hibridnost je tu delovala izključno

Giorgio Bernardi Perini, »Macaronica verba«, 327

Dirk Sacré, "Makkaronische Dichtung« ločuje "prvotno« in "preneseno« rabo ter ima slednjo za problematično.

Predvsem s področja Padove; podoben primer iz istega časa je Corrado Padovanski, Tosontea.

José Miguel Domínguez Leal, »Primeras propuestas lingüístcas«.

Bernardi Perini, »Macaronica verba«, 327. 
kot sredstvo boljše razumljivosti v specifičnih socialno-kulturnih pogojih: kot vsakdanja potreba bolj omikanih oseb za stike s tistimi, ki takšne izobrazbe niso bili deležni. V teh primerih torej kvarjenje latinščine in jezikovno mešanje nimata humornega namena in prehajanje ni načrtovano. Nasprotno je pri makaronski latinščini prehajanje načrtovano in so napake namerne, dobro obvladovanje jezika pa je predpogoj za branje. ${ }^{49}$

Jezika torej ni mogoče poenostaviti na raven preproste jezikovne mešanice $\mathrm{z}$ namenom splošne razumljivosti tudi za manj izobražene, niti ga ne moremo uvrstiti zgolj na področje satire. Še posebej v padovanskem okolju, torej v samem središču humanistične kulture, je makaronščina načrtno kvarjenje latinščine opustila $\mathrm{v}$ prid duhovitega jezikovnega prehajanja, poleg tega pa jo je žlahtnila še tradicionalna verzna oblikovanost $\mathrm{v}$ heksametrih. ${ }^{50}$ Kot pravi Nodier, gre pravzaprav za svojevrsten dulce docere, ki bralca zabava in kultivira hkrati. ${ }^{51}$ Fabule takšnih pesnitev so bile običajno trivialne in pogosto komične, večinoma povezane $\mathrm{z}$ univerzitetnim okoljem. Na podlagi tega Perini za predhodnike makaronskih piscev šteje goliarde. ${ }^{52}$

Makaronščina se na začetku 15 . stoletja razširi po Italiji ${ }^{53}$ in preide še na druge teme. Marsikje slogovno opeša in nekatere bolj perifernih pesnitev so zgolj posnetki del v že omenjeni Küchenlatein. Za popolno prenovo in pravzaprav normiranje žanra je poskrbel Teofilo Folengo s pesnitvijo Baldus (1517)..$^{54}$ Očistil in izboljšal je jezik ter dokazal njegovo sprejemljivost: prvi ga je namreč uporabil $\mathrm{v}$ različnih književnih zvrsteh, poleg tega pa je reorganiziral heksameter, in sicer s trdno zvestobo pravilom klasične metrike. ${ }^{55} \mathrm{~S}$ takšno klasicistično obnovo $\mathrm{v}$ duhu humanizma je začrtal natančne

Domínguez Leal, »Primeras propuestas lingüístcas«.

Bernardi Perini, »Macaronica verba«, 328.

"Mikavnost makarononščine izhaja iz intelektualnega užitka ob povsem zasebnem prevajanju, ki hkrati pritegne in zabava duha; medtem ko branje prevoda v ljudskem jeziku nikoli ne more učinkovati povsem tako.« Nodier, "Du langage factice appelé macaronique«, 3-11, po Domínguez Leal, »Primeras propuestas lingüístcas«.

Bernardi Perini, »Macaronica verba«, 328.

V Cremoni Evangelista Fossa, Vergiliana; v Mantovi poezija Giovanija Giogia Alioneja, v Benetkah Gian Giacomo Bartolotti, Macharonea medicinalis. Ibid.

4 Sicer del Liber macaronices. Sledila so še tri makaronska dela: Opus Merlini Cocaii (1521), Macaronicorum poema (ok. 1530) in postumna Poemata (1552); Ann E. Mullaney, »Works of Teofilo Folengo (1491-1544) and Giovanni Battista Folengo (1490-1559), clever writers of poetry and prose in Latin, Italian and Macaronic Latin«.

55 Normula macaronica de sillabis (1521). Ibid. 
oblikovne smernice žanra in ga razločil od predhodnih poskusov. ${ }^{56}$ Pričakoval je izobraženo publiko in predpostavljal znanje klasične latinščine in razgledanost na področju antike. Zaradi značaja eruditske poezije so se Folengova dela hitro razširila tudi izven Italije ${ }^{57}$ in njegov slog so pogosto posnemali v evropskih humanističnih krogih, še posebej v pismih. ${ }^{58}$

Kot opozarja Gantar, je v slovenskem kulturnem okolju ta stilni žanr tako slabo poznan, da »SSKJ te oznake sploh ne registrira «. ${ }^{59}$ Zanimivo pa pridevnik »makaronski« s tem pomenom priznava starejši Pleteršnikov slovar, in sicer pomeni »iz dveh ali več jezikov«. ${ }^{60}$ Tudi izraz »makaronizem« ni zabeležen v nobenem od slovenskih normativnih jezikovnih priročnikov, četudi se v strokovni literaturi večkrat uporablja. Služi kot neke vrste termin za tujejezične besede, vstavljene v sicer enojezično besedilo poljubne književne zvrsti, ne pa kot stilistični kvalifikator ali žanrska oznaka, kakor bi bilo morda smiselno pri Lovrenčičevem delu.

Čeprav je namreč $\mathrm{v}$ pesnitvi mešanja precej manj kot pri italijanskih makaronskih piscih, se ob teh odlomkih ni mogoče upreti asociacijam na zgodnejša italijanska dela, ki sodijo med žanrske predstavnike - pred seboj imamo epsko pesnitev in mešanico »ljudskega« jezika ter latinščine. $\mathrm{Z}$ njimi ga povezuje tudi dejstvo, da pri Lovrenčiču do prehajanja $\mathrm{v}$ latinščino prihaja $\mathrm{v}$ navezavi na študentsko okolje in največkrat v situacijah s komičnim značajem, kakor na primer pri Tifiju Odasiju. Povezava se zdi še toliko pripravnejša zaradi vložene komedije, ki jo v pesnitvi

56 "Kar je bilo prej zgolj preprosto sredstvo za krajšanje časa, nekje med študentskim in meščanskim slogom, je v don Teofilovih rokah postalo rafiniran umetniški inštrument.« Bernardi Perini, »Macaronica verba«, 332.

57 Našemu prostoru so na primer najbolj poznane komedije Marina Držića (15081567); prim. Frano Čale, »Kultura humanizma i Držićev makaronski govor«, $161-73$.

58 Domínguez Leal, »Primeras propuestas lingüístcas«. Pisma v jezikovni mešanici $\mathrm{s}$ komičnim prizvokom so bila predvsem $\mathrm{v}$ večjezičnih deželah pogosta tudi v razsvetljenstvu. Pri nas sta za mojstra makaronizmov v epistolarnem slogu veljala Zois in Kopitar, slednji je v svoji knjižnici hranil tudi izvod Folengovega Balda. Luka Vidmar, Zoisova literarna republika, 120.

60 Maks Pleteršnik, »Slovensko-nemški slovar«. 
uprizorijo Joannesovi kolegi. Njen potek namreč zvesto sledi opisom uprizoritev humanističnih in zgodnje renesančnih komedij takšnega okolja, ${ }^{61}$ kar še močneje izpostavlja navezavo na takrat nastala dela.

Komičnost seveda ni glavni namen pesnitve, v ospredju ostaja faustovski motiv. ${ }^{62}$ A prav vezanost spevov, ki prehajajo v latinščino, na točno določeno vsebinsko ozadje, skupno italijanskim makaronskim piscem, odlomke nedvomno povezuje z omenjenimi deli. Kljub dejstvu, da slovenski književnosti jezikovno mešanje sicer ni neznano, stil teh odlomkov predstavlja svojevrsten fenomen, saj gre za več jezikov, drugačno književno vrsto ${ }^{63}$ in drugačno vsebino. Ta stilistična posebnost je nedvomno eden od številnih elementov Lovrenčičeve pesnitve, ki si zaslužijo podrobnejše obravnave in nenazadnje tudi upoštevanja pri splošno sprejeti opredelitvi pojma "makaronščina", ki kljub intenzivnim raziskavam zadnjih let še vedno ostaja deziderat. ${ }^{64}$ Po svoje priča o tem, kako kompleksno zasnovano je bilo delo avtorja, pri katerem je bila latinščina nerazdružljiv del njegovega miselnega repertoarja, ključni člen njegovega literarnega idioma, ki poleg pesnika in prevajalca ter vztrajnega pedagoga osvetljuje tudi razgledanega klasičnega filologa.

\section{BIBLIOGRAFIJA}

Bernardi Perini, Giorgio. »Macaronica verba: Il divenire di una trasgressione linguistica nel seno dell'umanesimo«. Integrazione mescolanza rifiuto: Incontri di popoli, lingue e culture in Europa dall'antichita all'umanesimo (2001): 327-36.

Bevk, France. »Fašistični strup«. Partizanski dnevnik, 23. januarja 1945.

Bjelčevič, Aleksander. "Slovenski svobodni verz do sredine tridesetih let 20. stoletja«. Słowiańska metryka porównawcza: Wiersz wolny 7 (1998): 205-45.

Brecelj, Marijan. »Bibliografija Jože Lovrenčiča». Goriški letnik 18 (1991): $125-158$.

61 V krogu študentov, ki so hkrati snovalci in izvajalci, in svoje produkte včasih na pol improvizirano izvajajo na dvorcih premožnih posameznikov; Antonio Stäuble, La commedia umanistica del quatrocento, 1968.

62 Za podrobnejšo obravnavo motiva glej Jože Kurinčič, »Sholar iz Trente - slovenski Faust«, 73-82.

63 Na podlagi tega povesti Med Scilo in Karibdo ne moremo uvrstiti v isti žanr: v njej namreč najdemo tudi nemščino in italijanščino, poleg tega pa ni pisana $\mathrm{v}$ verzni obliki.

64 Šime Demo, »Towards a Unified Definition of Macaronics«, 104. 
Čale, Frano. »Kultura humanizma i Držićev makaronski govor«. Mogućnosti: književnost, umjetnost, kulturni problemi 38, št. 1/2 (1991): 207-222.

Demo, Šime. »Mining Macaronics«. V: Multilingual Practices in Language History: English and Beyond, ur. Päivi Pahta, Janne Skaffari in Laura Wright, 199-221. Berlin: De Gruyter Mouton, 2018.

—_ . »Towards a Unified Definition of Macaronics«. Humanistica Lovaniensia 63 (2014): 83-106.

Dolenc, Janez. »Folklorne prvine v delih Joža Lovrenčiča«. Goriški letnik 18 (1991): 89-95.

Domínguez Leal, José Miguel. »Primeras propuestas lingüístcas sobre el macarroneo«. V: La poesía macarrónica en España, poesiamacarronica. blogspot.

»Elementi ekspresionizma pri Joži Lovrenčiču«. V: Arhiv Joža Lovrenčiča, ur. Oddelek za klasično filologijo, FF UL.

Gantar, Kajetan. »Joža Lovrenčič in antika«. Goriški letnik 18 (1991): 102-7.

Grafenauer, Ivan. »O naših najmlajših«. Dom in svet 18 (1915).

Kores, Darinko. »Joža Lovrenčič: Sholar iz Trente: ob štiridesetletnici pisateljeve smrti«. Dialogi 29.3 (1993): 24-42; 29.4 (1993): 55-64.

Kurinčič, Jože. »Sholar iz Trente - slovenski Faust«. Goriški letnik 18 (1991): 73-82.

Lovrenčič, Joža. Med Scilo in Karibdo. Gorica: Goriška Mohorjeva družba, 1954.

—_ . »Nič Niče«. V: Arhiv Jože Lovrenčiča, ur. 1949; Oddelek za klasično filologijo FF UL.

—_. Sholar iz Trente. Ljubljana: Jugoslovanska knjigarna, 1939.

—. Ves vaš ljubeči očka: Pisma hčerki Nini. Gorica: Goriška Mohorjeva družba, 2010.

Melnik, Branko. »Staro in novo v pesniškem opusu Joža Lovrenčiča«. Goriški letnik 18 (1991): 69-72.

Movrin, David. »Dr. Joža Lovrenčič in njegove zakopane Metamorfoze«. Keria 19, št. 2 (2017): 65-80.

Mullaney, Ann E. »Works of Teofilo Folengo (1491-1544) and Giovanni Battista Folengo (1490-1559), clever writers of poetry and prose in Latin, Italian and Macaronic Latin«. www.folengo.com.

Sacré, Dirk. »Makkaronische Dichtung«. V: Der Neue Pauly: Enzyklopädie der Antike, Rezeptions- und Wissenschaftsgeschichte, ur. Hubert Cancik in Helmuth Schneider, 281-85. Leiden: Brill, 2007.

Slodnjak, Anton. Slovensko slovstvo. Ljubljana: Mladinska knjiga, 1968.

Stäuble, Antonio. La commedia umanistica del quatrocento. Firence: Instituto Nazionale di Studi sul Rinascimento, 1968.

Vidmar, Luka. Zoisova literarna republika: Vloga pisma $v$ narodnih prerodih Slovencev in Slovanov. Ljubljana: ZRC SAZU, 2010 


\section{IZVLEČEK}

Članek obravnava literarno ustvarjanje dr. Joža Lovrenčiča (18901952), slovenskega pesnika, pisatelja, prevajalca in klasičnega filologa. Prinaša nekatere življenjepisne informacije in na njihovi podlagi obravnava zlasti njegovo afiniteto do rimske in grške antike. $S$ tem $\mathrm{v}$ zvezi se posveča njegovi mladostni povesti Med Scilo in Karibdo in epski pesnitvi Sholar iz Trente (1939). Še posebej pri slednji je najti vrsto navezav in citatov iz klasičnega sveta, hkrati pa pesnitev na več mestih $s$ slovenščino meša latinske besede ali v latinščino celo povsem preide. Te odlomke je tudi vsebinsko mogoče povezati z literarnim slogom makaronske latinščine.

KLJUČNE BESEDE: Joža Lovrenčič, Sholar iz Trente, Med Scilo in Karibdo, makaronizmi, makaronska latinščina 


\section{JOŽA LOVRENČIČ AND MACARONIC LATIN \\ IN THE SCHOLAR FROM TRENTA}

\section{ABSTRACT}

The study analyzes the literary opus of dr. Joža Lovrenčič (18901952), a Slovenian poet, writer, translator, and classicist. Pointing out several details in his curriculum vitae, it deals primarily with his affinity for Graeco-Roman antiquity. A case in point is one of his early works, a story entitled Between Scylla and Charybdis, as well as his epic poem The Scholar from Trenta (1939). The Scholar from Trenta, in particular, employs a series of allusions as well as quotations from classical antiquity. It often blends Slovenian with Latin, sometimes changing the idiom completely. The literary style in these passages can be best described as macaronic Latin.

KEYWORDS: Joža Lovrenčič, The Scholar from Trenta, Between Scylla and Charybdis, macaronisms, macaronic Latin 